\title{
Nematicidal activity of aqueous and organic extracts of local plants against Meloidogyne incognita (Kofoid and White) Chitwood in Algeria under laboratory and greenhouse conditions
}

Sabri Ala Eddine Zaidat ${ }^{*}$, Fazia Mouhouche ${ }^{1}$, Djaafar Babaali ${ }^{1}$, Nesma Abdessemed ${ }^{2}$, Miguel De Cara $^{3}$ and Miloude Hammache ${ }^{1}$

\begin{abstract}
The nematicidal efficiency of two types of extracts (aqueous and methanolic) of 5 plants Peganum harmala L., Raphanus raphanistrum L., Taxus baccata L., Sinapis arvensis L., and Ricinus communis L. on second stage juveniles (J2s) of Meloidogyne incognita was evaluated at 4 doses in vitro $(40,50,60$ and $80 \%)$ at 4 exposure times $(12,16,24$, and $32 \mathrm{~h}$ ). In a greenhouse, methanol extracts obtained from $0.75,1.5$, or $3 \mathrm{~g}$ of the dry matter of T. baccata, $\mathrm{S}$. arvensis, and $P$. harmala were added in pots of tomato plants (Moneymaker cultivar) to test the effect of the extracts on the nematode, its reproduction, and the plant's growth. After $32 \mathrm{~h}$ of exposure, the in vitro results on $\mathrm{J} 2 \mathrm{~s}$ showed that all the aqueous and methanolic extracts of the 5 plants had positive effects on $\mathrm{J} 2$ mortality compared to controls; water and DMSO (2\%) (dimethyl sulfoxyde). In general, methanolic extracts were significantly more effective than the aqueous ones. Methanolic extracts of T. baccata, P. harmala, and S. arvensis had the highest mortality rates $(100,89.2,86.6 \%)$, respectively, followed by the aqueous extract of $T$. baccata (73.8\%). After 12 days, the hatching inhibition varies between (61.4\%) for the aqueous extract of $R$. communis and (84.2\%) for the methanolic extract of T. baccata. The average was significantly different from controls (DMSO 23.8 and water 21.8\%) for all extracts. Methanolic extracts were not always significantly different than the aqueous ones. In vivo methanolic extracts of S. arvensis, P. harmala, and T. baccata reduced infestation than the controls. The gall index varied between 3.5 and 5.5 for the extracts than the positive control 6.5. The present study revealed the effectiveness of all tested plant extracts to root-knot nematodes without any chemical inputs.
\end{abstract}

Keywords: Meloidogyne incognita, Plant extracts, Hatch suppression, Juvenile mortality

\section{Background}

Cecidogenic nematodes are pests that cause serious damage to several crops, mainly horticulture (Adegbite et al. 2005). Crop production problems induced by nematodes therefore generally occur as a result of root

\footnotetext{
* Correspondence: zaidatsabri@hotmail.com

'Département de Zoologie Agricole et Forestière, Ecole Nationale Supérieure d'Agronomie, 1 Avenue Hassan Badi, El-Harrach, 16200 Algiers, Algeria Full list of author information is available at the end of the article
}

dysfunction, reducing rooting volume and foraging and utilization efficiency of water and nutrients (Hemlata and Jyoti 2018).

In Algeria, the distribution of Meloidogyne nematodes affects areas of high vegetable crop productivity (Alger, Constantine, Biskra, Ouargla, Adrar) (Babaali et al. 2016). Several methods are available to control the plant parasitic nematodes. Synthetic nematicides are used most often compared to other known nematode control

\section{Springer Open}

( ) The Author(s). 2020 Open Access This article is licensed under a Creative Commons Attribution 4.0 International License, which permits use, sharing, adaptation, distribution and reproduction in any medium or format, as long as you give appropriate credit to the original author(s) and the source, provide a link to the Creative Commons licence, and indicate if changes were made. The images or other third party material in this article are included in the article's Creative Commons licence, unless indicated otherwise in a credit line to the material. If material is not included in the article's Creative Commons licence and your intended use is not permitted by statutory regulation or exceeds the permitted use, you will need to obtain permission directly from the copyright holder. To view a copy of this licence, visit http://creativecommons.org/licenses/by/4.0/. 
strategies because they are effective and quick in action (Odeyemi et al. 2013). The indiscriminate use of synthetic pesticides to control nematodes was likely to give rise to phytotoxicity, environmental pollution, and resistance to nematodes, in addition to its very high cost (Adegbite et al. 2005). The growing concern for the environment and the recent ban on many nematicides has required a reduction in the amount of chemical nematicides and the development of non-chemical options (Odeyemi et al. 2013).In addition, the search for effective, environmentally sound and safe alternative control methods has been intensified.

One of the possible alternatives is the utilization of biopesticides from plant origin, known as botanical pesticides (Javed et al. 2007). These biopesticides are generally considered to be non-persistent under field conditions as they are readily transformed by light, oxygen, and microorganisms into less toxic products (Wiratno et al. 2009). Numerous plant species, representing 57 families including Lamiaceae, Asteraceae, Myrtaceae, Rutaceae, and Lauraceae, can contain nematicidal compounds (Andrés et al. 2012). The use of plant extracts as an alternative tool to synthetic pesticides for control of root-knot nematode has become important (Kepenekçi et al. 2016). The use of plant extracts against Meloidogyne spp. has shown their effectiveness in several previous studies (Hassan et al. 2013; Curto et al. 2015; Xia et al. 2019).

The objective of the present work was evaluation of juvicidal and ovicidal potential of aqueous and organic extracts of 5 local plants on Meloidogyne incognita under controlled conditions.

\section{Materials and methods}

\section{Plant extracts}

Five plants (Peganum harmala, Raphanus raphanistrum, Taxus baccata, Sinapis arvensis, and Ricinus communis), belong to 4 different botanical families, were collected at their vegetative stage from different regions of Algeria at different bioclimatic levels in 2017.The collected plants were identified using voucher specimens deposited in the herbarium of the Botany Department of Ecole Nationale Supérieure d'Agronomie (ENSA, ex. INA, Algiers, Algeria); identification was further confirmed by $B$. FARSSI, Doctor of Ecology in the same Department. Plant leaves were dried in shade for 15 days under laboratory conditions and then turned to fine powders using a commercial grinder.

The species used (wild rue, wild radish, field mustard, and castor bean) were chosen because of their nematicidal effects as shown in several previous studies (Hassan et al. 2013; Curto et al. 2015; Xia et al. 2019). T. baccata was chosen for its medicinal properties and it has not been tested previously on nematodes (Guenard et al.
1993). In order to prepare the inoculum and/or in plant test, tomato plants were used. The seeds of tomato ( $\mathrm{So}$ lanum lycopersicum L. cv. Moneymaker, Solanaceae) were sown in alveolate plates and raised in a greenhouse for 1 month, and then the seedlings were transplanted into $2.5 \mathrm{~L}$ plastic pots $(17.5 \times 14.5 \mathrm{~cm}$ : diameter $\times$ height) containing $1 \mathrm{~L}$ of a sand mold mixture (1/2:1/2).

\section{Preparation of aqueous and organic extracts}

Two types of extracts (organic and aqueous) were used in this study. A quantity of $25 \mathrm{~g}$ of powder of each plant species ( $P$. harmala, $R$. raphanistrum, T. baccata, $S$. arvensis, and $R$. communis) was placed in $500 \mathrm{ml}$ glass flasks containing $250 \mathrm{ml}$ of solvent (distilled water or methanol at $80 \%$ for aqueous or organic extraction, respectively) (Dane et al. 2015). The flasks were placed under an orbital shaker (Ika-Werke-GMBH \& CO.KG D-79219 Staufen, Germany) for $4 \mathrm{~h}$ at 500 $\mathrm{rpm}$. The mixture was filtered through a funnel equipped with filter paper $\left(\mathrm{N}^{\circ} 1 ; 100 \mu \mathrm{m}\right)$ and centrifuged (Horizontal centrifuge, Swing-3000, Apogee, Germany) for $15 \mathrm{~min}$ at $1500 \mathrm{rpm}$ to remove debris. The solvent (methanol) of the organic extract was evaporated using the Rotavapor (Laborgerate, $\mathrm{GmbH}$, ISOLAB) at $60^{\circ} \mathrm{C}$, while the water of aqueous extract was evaporated by water bath (LWB-111D, LabTech, Korea) at $60^{\circ} \mathrm{C}$. All quantities obtained from aqueous extracts after evaporation were diluted by $25 \mathrm{ml}$ of distilled water, while the methanolic extracts were diluted by $25 \mathrm{ml}$ of DMSO (2\%) (dimethyl sulfoxyde). The solution was considered as a stock solution and stored at $4{ }^{\circ} \mathrm{C}$ for up to $24 \mathrm{~h}$. (Babaali et al. 2017).

\section{Nematode inoculum}

Tomato roots infected with Meloidogyne incognita were sampled from the Staoueli region $(25 \mathrm{~km}$ west of Algiers, Algeria) and transferred to the laboratory. The egg masses were carefully detached from the roots and placed in hatchers containing sterile distilled water (SDW). After $48 \mathrm{~h}$, the juveniles were recovered in graduated beakers. One milliliter of the suspension was collected and observed under an optical microscope to determine the number of existing J2s in the solution (the recommended concentration of J2s of inoculum was always adjusted by adding sterile distilled water for juveniles). This step was repeated at least 10 times. The multiplication of the number of juveniles (J2s) was carried out on tomato seedlings (Moneymaker cultivar) on greenhouse at experimental station of ENSA. The tomato seedlings were inoculated 1 month after transplanting by $2500 \mathrm{~J} 2 \mathrm{~s}$ (tomato seedlings were irrigated regularly for 60 days). After 2 months, fresh egg masses were collected and hatched. 
Table 1 Percentages of the different volumes of the stock solution in the juvenile mortality test

\begin{tabular}{lllll}
\hline Juvenile suspension $(1 \mathrm{ml})$ & & & & \\
\hline Volumes of stock solution $(\mathrm{ml})$ & 0.8 & 0.6 & 0.5 & 0.4 \\
Percentages (\%) & 80 & 60 & 50 & 40 \\
\hline
\end{tabular}

\section{Biological assays}

In vitro test

Juveniles mortality bioassay The effect of aqueous and organic (methanolic) extracts at various concentrations (Table 1), obtained from the stock solution (considering that $1 \mathrm{ml}$ of stock solution with $1 \mathrm{ml}$ of $\mathrm{J} 2 \mathrm{~s}$ suspension was the $100 \%$ concentration) on the juveniles of $48 \mathrm{~h}$ was evaluated. One milliliter nematode suspension $>100$ $\mathrm{J} 2 \mathrm{~s}$ in a 24-well plate maintained in an incubator, in the dark, at $24{ }^{\circ} \mathrm{C}$. Each treatment was repeated 5 times. Using a double counter, $100 \mathrm{~J} 2 \mathrm{~s}$ between dead and live juveniles were counted after 12, 16, 24, and $32 \mathrm{~h}$ of exposure considering a young straight or motionless juvenile as dead, which was confirmed by touching them with a fine needle. To compare the results, natural mortality was counted in water and in DMSO at $2 \%$ and they were considered as controls. The lethal concentration $\left(\mathrm{LC}_{50}\right)$ to exterminate $50 \%$ of juveniles was calculated using probit analysis (Bliss 1934).

Hatching bioassay For the evaluation of the effect of the 2 types of extracts (aqueous and organic) at the same concentrations, used in the previous test on the hatching of $M$. incognita eggs, a suspension was prepared from the eggs extracted from the tomato roots with a $0.5 \%$ $\mathrm{NaOCl}$ (sodium hypochlorite) solution, knowing that the $M$. incognita eggs were obtained by passing the solution through a $250-\mu \mathrm{m}$ sieve and rinsing the eggs with sterile water in a $25-\mu \mathrm{m}$ sieve (Hussey and Barker 1973). Each treatment consisted of 5 replicates of 100 eggs in $1 \mathrm{ml}$ of each extract concentration. The experiment was conducted in 24-well plate maintained in an incubator, in the dark, at $24^{\circ} \mathrm{C}$. Hatched J2s were counted after 12 days in treatments. The controls used were eggs treated with DMSO (2\%) and eggs treated with sterile distilled water (Babaali et al. 2017). The hatching inhibition rate $\mathrm{R}$ (HI) was calculated using the following formula:

$$
\mathrm{R}(\mathrm{HI})=[(\mathrm{Nie}-\mathrm{Neh}) / \mathrm{Nie}] * 100
$$

where Nie is the initial number of eggs and Neh is the number of eggs hatched.
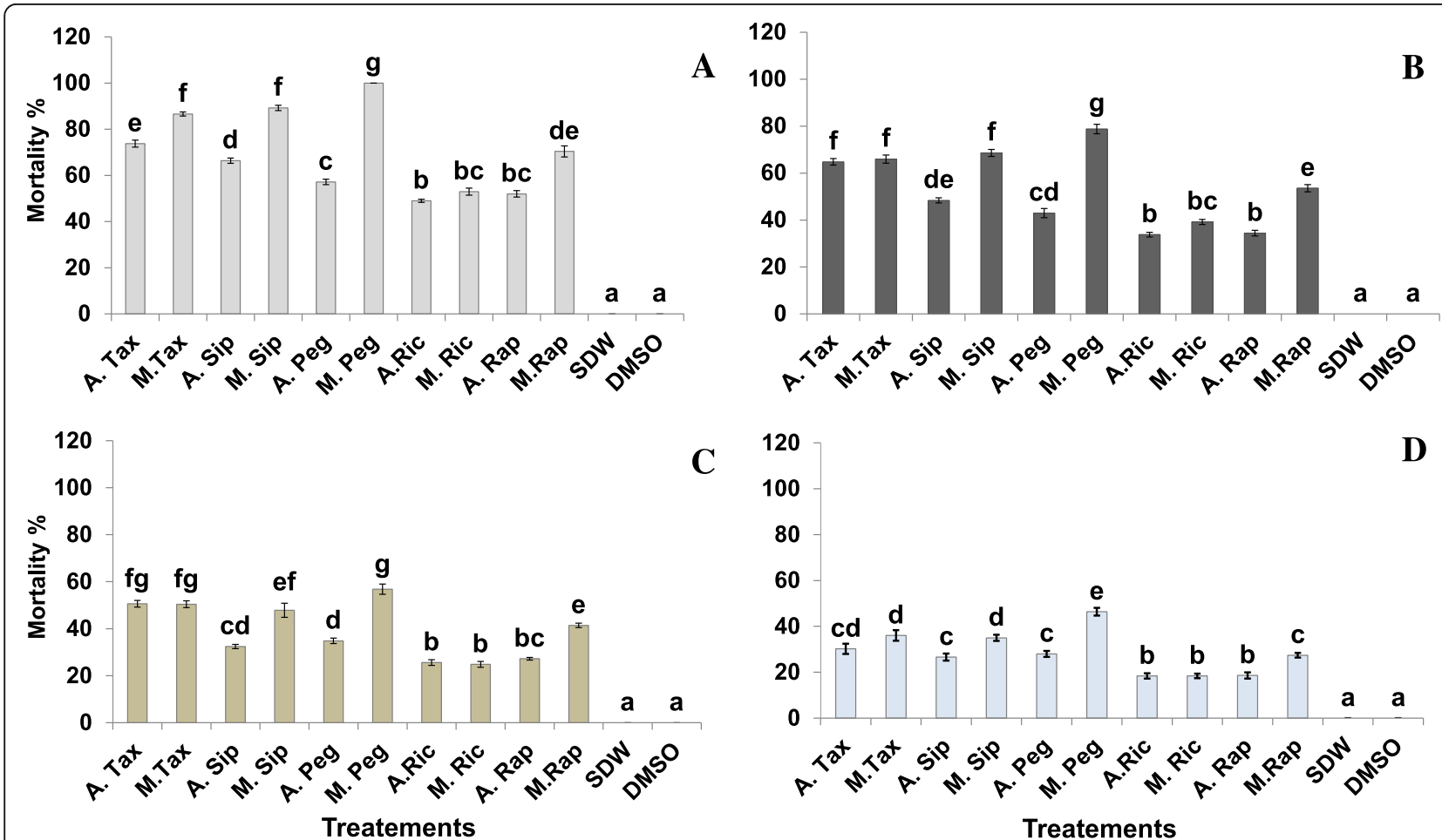

Fig. 1 Effect of different aqueous (A) and methanolic (M) extracts at various concentrations (a 80\%, b 60\%, c 50\%, and d 40\%) on mortality of Meloidogyne incognita juveniles (J2s) after 32 h. Tax T. baccata, Peg. P. harmala, Sin. S. arvensis, Rap. R. raphanistrum, Ric R. communis, SDW sterile distilled water, DMSO dimethylsulfoxyde 

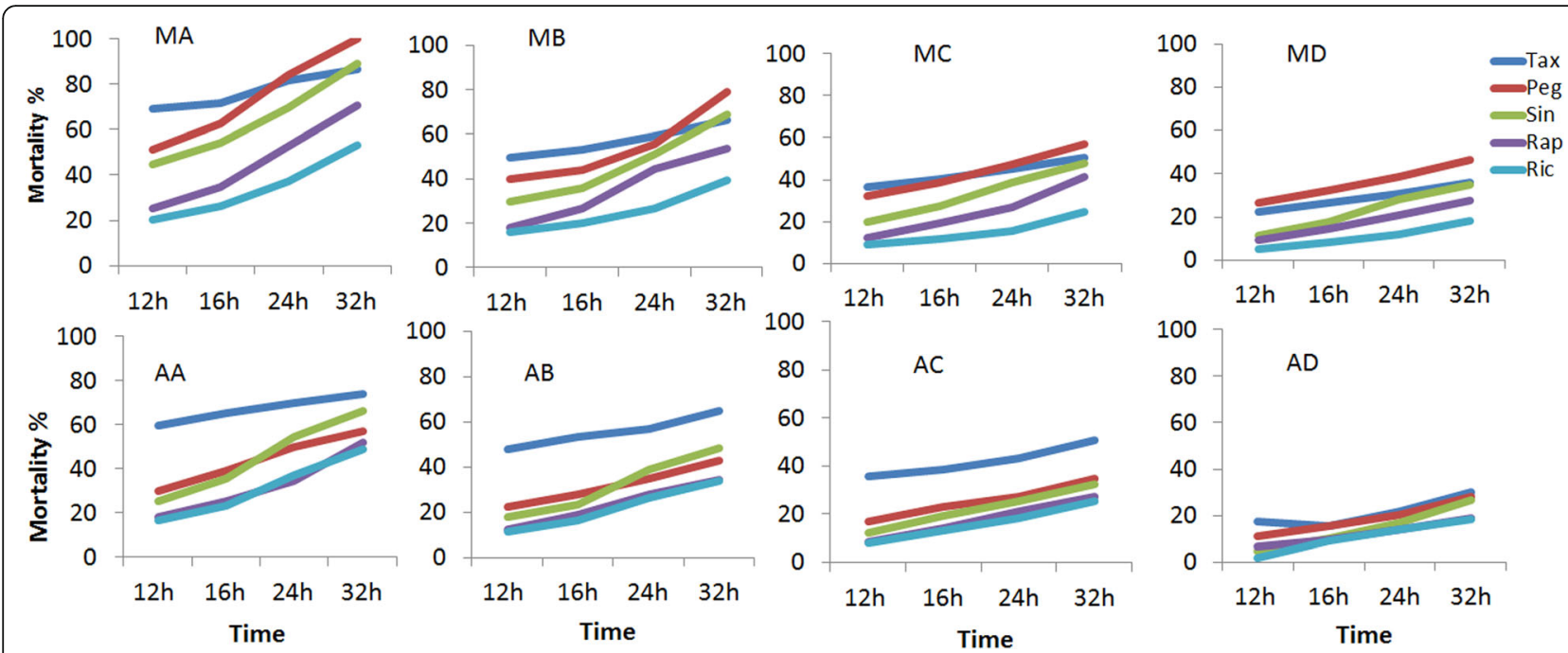

Fig. 2 Effect of different aqueous (A) and methanolic (M) extracts at various concentrations (a $80 \%, \mathbf{b} 60 \%$, c $50 \%$, and $\mathbf{d} 40 \%$ ) on mortality of $M$. incognita juveniles (J2s) during exposure times. Tax T. baccata, Peg. P. harmala, Sin. S. arvensis, Rap. R. raphanistrum, Ric R. communis

In vivo infestation of nematodes into roots of the tomato bioassay To confirm the results obtained in vitro, plant test was performed. In this test, the methanolic extracts used were $P$. harmala, $T$. baccata, and $S$. arvensis (their doses were 3, 1.5, and $0.75 \mathrm{ml}$ for each dose, and water was added to reach $20 \mathrm{ml}$ ). This experiment was conducted in pots using tomato seedlings of the Moneymaker cultivar, which is very sensitive to $M$. incognita under greenhouses. The treatments were applied 1 day before transplanting the tomato seedlings. After 1 day of transplantation, $1500 \mathrm{~J} 2 \mathrm{~s}$ (48 h old) were deposited in 5 holes around the stem at a depth of $3 \mathrm{~cm}$. Unlike the positive control seedlings, which were treated by the nematodes juveniles and by sterile distilled water, the negative control seedlings were treated by sterile distilled water only. Each treatment was repeated 6 times. At the end of the test, the infestation parameters (galls index, number of juveniles per root, number of galls, and number of egg masses) and growth parameters (dry weight of the aerial part and of the root) were estimated. The gall index was estimated according to Zeck's rating of 1 to 10 (Zeck 1971).
Data processing Experiments were conducted in a complete randomized design. The data were performed by the analysis of variance (two-way ANOVA) for juvenile mortality and for in vivo test parameters, three-way ANOVA for egg hatching, and their means were compared, using HSD of Tukey at $P<0.05$, using the STATISTICA software (Statistica version 8.5 year 2014).

\section{Results and discussion}

The two types of extracts of the 5 plant species at different concentrations and at different times of exposure showed different effects on the J2s mortality rate, on the hatching rate, and on the degree of infestation of juveniles in the roots of tomato plants. To the best of our knowledge, this is the first time that the leaves of local species; P. harmala, T. baccata, R. raphanistrum, and $R$. communis have been tested. Various plant species have been studied as a potential biocontrol tool against $M$. incognita and were therefore proposed as nematicidal. This was the case for Artemisia vulgaris L., Azadirachta indica A. Jass, roots of Ricinu scommunis L., Nicotiana tabacum L., Syzygiumaromaticum L., Piper betle L., Capsicum

Table 2 Lethal concentration $50\left(\mathrm{LC}_{50}\right)$ of the effect of extracts on M.incognita $\mathrm{J} 2 \mathrm{~s}$ mortality after $32 \mathrm{~h}$ of treatment

\begin{tabular}{|c|c|c|c|c|}
\hline \multirow[t]{2}{*}{ Species } & \multicolumn{2}{|l|}{ Methanolic extract } & \multicolumn{2}{|l|}{ Aqueous extract } \\
\hline & $\mathrm{LC}_{50}(\mathrm{ml} / \mathrm{mlwate})$ & Slope & $\mathrm{LC}_{50}(\mathrm{ml} / \mathrm{m}$ lwate $)$ & Slope \\
\hline T. baccata & 0.43 & $y=4.9306 x-8.2421$ & 0.51 & $y=3.8489 x-5.4401$ \\
\hline P. harmala & 0.44 & $y=10.64 x-23.221$ & 0.69 & $y=3.4938 x-4.908$ \\
\hline S. arvensis & 0.48 & $y=5.5311 x-9.8702$ & 0.62 & $y=3.6387 x-5.1658$ \\
\hline R. raphanistrum & 0.57 & $y=3.7723 x-5.4048$ & 0.78 & $y=3.1408 x-4.0865$ \\
\hline R. communis & 0.75 & $y=3.4586 x-4.9463$ & 0.83 & $y=2.9389 x-3.5748$ \\
\hline
\end{tabular}




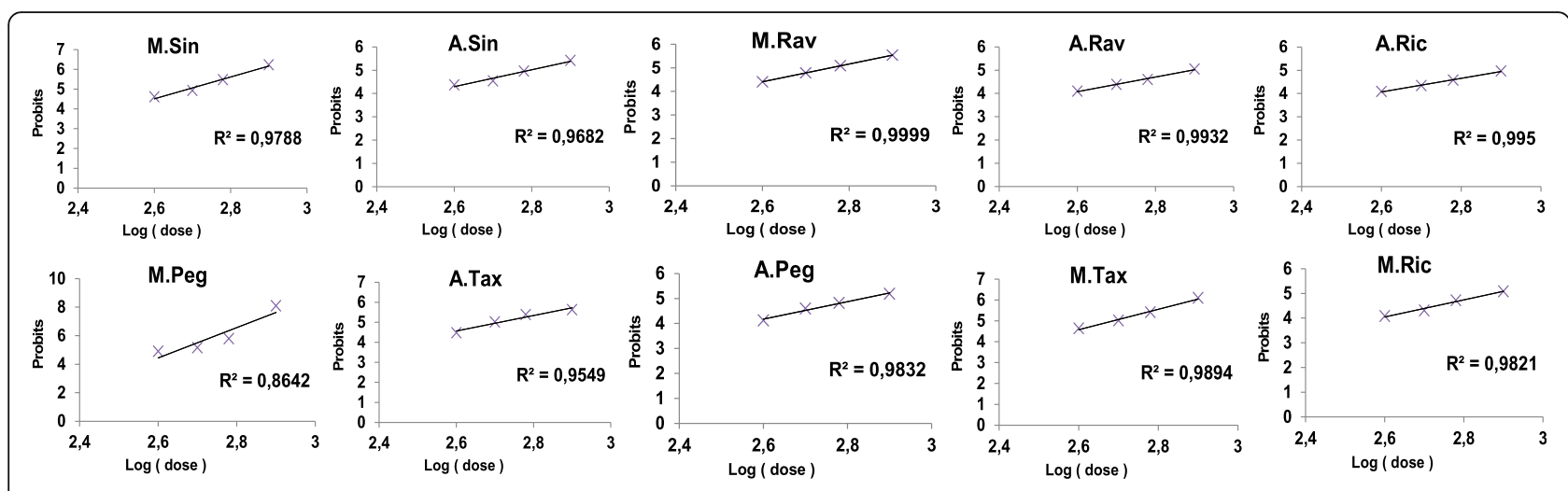

Fig. 3 Probit regression line at the different concentrations used of the aqueous (A) and methanolic (M) extracts of S. arvensis (Sin), P. harmala (peg), T. baccata (Tax), R. communis (Ric), and R. raphanistrum on juveniles (J2s) of M.incognita after $32 \mathrm{~h}$ of treatment

annuиm L., Zingiber officinale Roscoe, Parkiabiglobosa (Jacq.), Datura stramonium L., and Datura innoxia Mill. (Costa et al. 2003; Adegbite and Adesiyan 2005; Wiratno et al. 2009; Bawa et al. 2014; Babaali et al. 2017).

\section{In vitro test}

\section{Effect of plants extract on the juveniles mortality}

The two types (methanolic or aqueous) of extracts from the 5 tested plants (P. harmala, $R$. raphanistrum, T. baccata, $S$. arvensis, and $R$. communis) showed efficacy on M.incognita J2s (Fig. 1). The results are confirmed by Rich et al. (1989), Hassan et al. (2013), and Curto et al. (2015), when they used the seed extracts of Ricinus communis and Peganum harmala and the extracts of the 3 brassicaceae species of (Eruca sativa, Raphanu ssativus sp. oleiformis, Reseda luteola) on Meloidogyne juveniles, and found them effective.
This effect was consistent with the increase in concentration and the exposure period (Fig. 2), which is consistent with that reported by (Adegbite and Adesiyan 2005; Chaudhary et al. 2013; Kepenekçi et al. 2016).

The species, $T$. baccata and $P$. harmala, showed the highest nematicidal effect as they acted quickly with a shock effect from the first hours of immersion $(12 \mathrm{~h}) \mathrm{J} 2 \mathrm{~s}$. At the highest concentration (80\%), the mortality rate of J2s treated with methanolic extracts of T.baccata and P.harmala reached 69 and 51\%, respectively, while the mortality rate of J2s treated with methanolic extracts of S.arvensis and R.raphanistrum was lower. It reached 44 and $25 \%$, respectively. Moreover, the lowest mortality rate of methanol extracts was recorded at R.communis with $20.2 \%$. Mortality rates of J2s treated with aqueous extracts of T.baccata, P.harmala, S. arvensis, $R$.

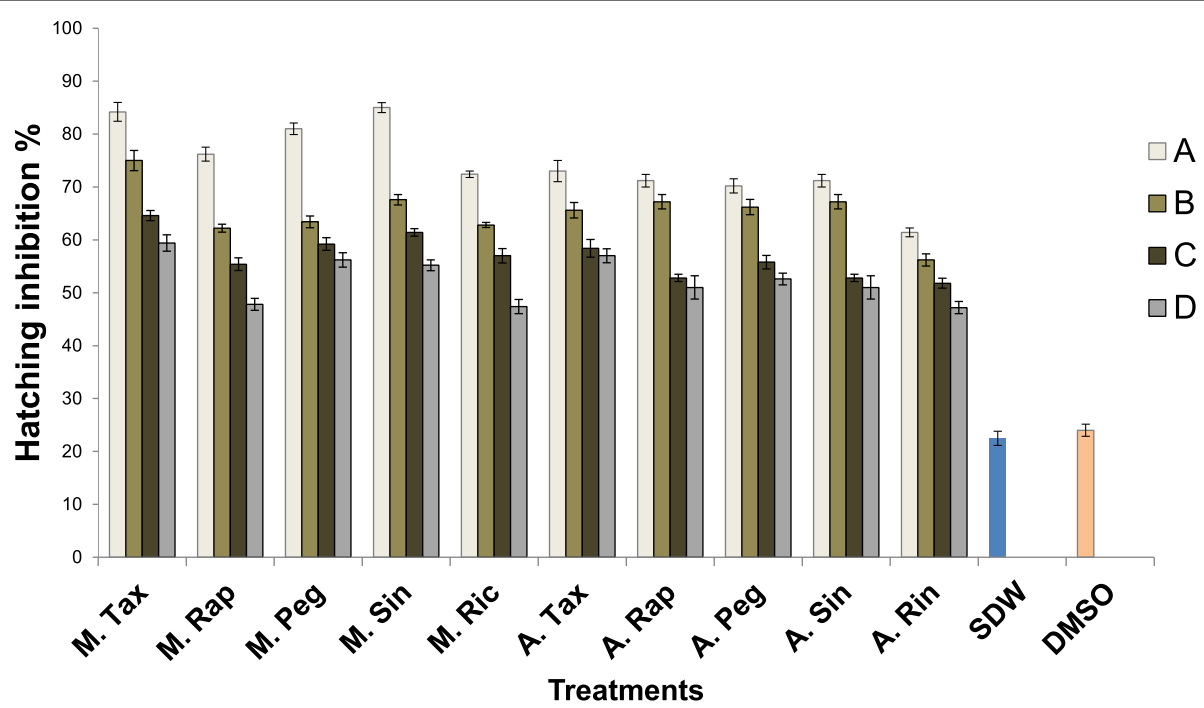

Fig. 4 Effect of plants extract at various exposure concentrations (A: 80\%, B: 60\%, C: 50\% and D: 40\%) on hatch of Meloidogyne incognita juveniles after 12-day incubation A: aqueous, M: methanolic, Tax: T.baccata, Peg.: P. harmala, Sin.: S. arvensis, Rap.: R. raphanistrum, Ric.: R. communis, SDW: sterile distilled water and DMSO: Dimethylsulfoxyde 


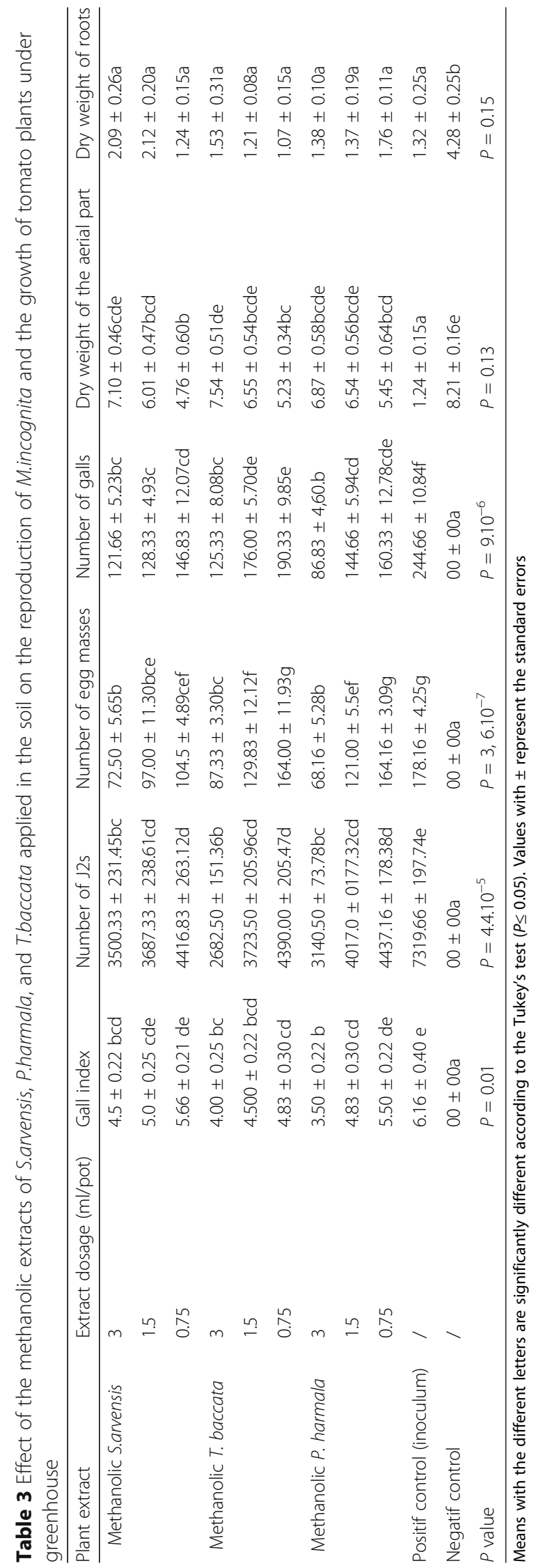


raphanistrum, and $R$. communis at the same exposure time and the same concentration attained 59, 30, 25, 18, and $16.2 \%$ respectively. After $32 \mathrm{~h}$, the percentage of mortality reached $100 \%$ at $80 \%$ by the methanolic extract of P.harmala. The same extract of S.arvensis recorded a considerable increase up to $89.2 \%$ unlike the extract of T.baccata, which showed an irregular increase to reach $86.6 \%$. The best aqueous extracts were of $T$. baccata, which caused a mortality rate of 73.8 at $80 \%$ after $32 \mathrm{~h}$ of exposure, exceeding the recorded rate of 70.4 and $53 \%$ for methanolic extracts $(80 \%, 32 \mathrm{~h})$ of $R$. raphanistrum and $R$. communis, respectively. In this test, the lowest mortality rate $(1.8 \%)$ was recorded in juveniles treated with aqueous extract of R.communis at a concentration of $40 \%$ and exposure time of $12 \mathrm{~h}$, followed by mortality rates of $4.6,6.4,5.4$, and $9.2 \%$ and recorded in juveniles treated with aqueous extract of $S$. arvensis and $R$. raphanistrum and with methanolic extract of $R$. communis and $R$. raphanistrum, respectively. Obtained results showed that the organic extract had better efficacy than the aqueous one on $\mathrm{J} 2 \mathrm{~s}$ at the 4 concentrations and all exposures times.

The results presented in (Table 2 and Fig. 3) showed that the $\mathrm{LC}_{50}$ values calculated for the $32 \mathrm{~h}$ of exposure time ranged from $0.43 \mathrm{ml} / \mathrm{ml}$ (methanolic extract of T.baccata) to $0.83 \mathrm{ml} / \mathrm{ml}$ (aqueous extract of $R$. communis). The highest $\mathrm{LC}_{50}$ of all methanolic extracts expresed by $0.75 \mathrm{ml} / \mathrm{ml}$ (extract of R.communis) and the lowest $\mathrm{LC}_{50}$ of all aqueous extracts by $0.51 \mathrm{ml} / \mathrm{ml}$ (extract of $T$. baccata).

\section{Effect of plants extracts on egg hatching of M.incognita}

Different extracts (metanolic and aqueous) of the tested 5 plants showed very highly significant effects $(P=5$, $3.10^{-5}$ ) on egg hatching. After 12 days of exposure of $M$. incognita eggs to the various extracts, significant differences with the DMSO $2 \%$ and water controls recorded egg hatch inhibition of 23.8 and $21.8 \%$, respectively (Fig. 4). The inhibition rate varied between 47.2 at $40 \%$ for the aqueous extract of $R$. communis and 85.2 at $80 \%$ for the methanolic extract of $S$. arvensis, followed by the methanolic extracts of $T$. baccata and $P$. harmala at the same dose with 84.2 and $81 \%$, respectively. Concerning the juveniles, the methanolic extract of $P$. harmala gave (100\%) mortality rate; the methanolic and aqueous extracts of $R$. communis had a better yield than its juvicidal effect. The percentage of inhibition in hatching increased with the increase of the concentration of the extracts from 40 to $80 \%$. In the present study, the efficacy of methanolic extracts compared to aqueous extracts was also verified for the hatch inhibition of M.incognita eggs. Similarly, in previous studies, they reported that the effect of organic extracts was better than the effect of aqueous extracts, and the rate of egg inhibition increased by increasing the concentrations of extracts (Chaudhary et al. 2013; Kepenekçi et al. 2016; Babaali et al. 2017).

\section{In vivo test \\ Effect of plant extracts on root infestation of nematodes}

At the end of the test, the roots of the tomato plants inoculated with the suspension of juveniles of M.incognita and treated with the 3 selected plant extracts $(S$. arvensis, $P$. harmala and T. baccata) that showed symptoms of disease (galls) with different degrees of infestation. The variance analysis at two factors (plants extracts and doses) of the methanolic extracts of the 3 selected plants showed 2 effects on the index of M.incognita infestation: one significant and the other highly significant on the roots of tomato seedlings, and 2 effects on growth parameters (dry weights of the aerial part and the roots): one significant and the other non-insignificant (Table 3). $P$. harmala extract showed a significant difference than other extracts to reduce M.incognita infestation for the highest concentration, while it ranked 2nd in reducing the number of juveniles after T. baccata extract. The efficacy of the methanol extracts of the 3 plants increased at the high concentration but it was different from one parameter to another. The reduction of the infestation rate and number of galls on the roots after the application of the 3 metanolic extracts of the 3 plants was at the same line with other researches like that Costa et al. (2003), Wiratno et al. (2009), and Bawa et al. (2014).

These results can be attributed to the presence of toxic substances released by the extracts such as alkaloids, flavonoids, saponins, and amides including benzamide and ketones, which have juvicidal and ovocidal potentials and can effect singly or combination (Adegbite and Adesiyan 2005). Peganum harmala, Taxus baccata, and Ricinus communis have always been known for their biological activities (medicinal, antibacterial, antifungal, antioxidant, insecticide) (Nenaah 2010;Behidj-Benyounes et al. 2014; Bhakta and Das 2015; Abbassi et al. 2015 and Wilson and Hooser 2018).

\section{Conclusion}

Obtained results suggest that $P$. harmala, $R$. raphanistrum, T. baccata, $S$. arvensis, and $R$. communis have potentials as nematicidal on Melodoigyne incognita, especially when applied in a methanolic solvent. A study of the biochemical composition of these 5 plants and detection of molecules with nematicidal potential is worth for further researches. These species are well adapted to humid, arid, and semi-arid conditions, where wild tomato is cultivated, and M.incognita is its common threat.

\section{Abbreviations}

A: Aqueous; DMSO: Dimethyl sulfoxyde; E: East; ENSA: Ecole Nationale Supérieure d'Agronomie; J2s: Juvenile of second stage juveniles; LC 
50: Lethal concentration 50; M: Methanolic; N: North; NaOCl: Sodium hypochlorite; Nhe: Number of eggs hatched; Nie: Initial number of eggs; Peg: Peganum harmala; R (hi): Rate of hatching inhibition; Rap: Raphanus raphanistrum; Ric: Ricinus communis; RKNs: Root-knot nematode; SDW: Sterile distilled water; Sin: Sinapis arvensis; Tax: Taxus baccata

\section{Acknowledgements}

The authors would like to thank Mr G. Kaci for his contribution in the statistical analyses, Mr S. Bouzaa for his contribution in the experiment, and Ms F. Abdessemed for her assistance in English correction. We also want to thank the National Institute of Plant Protection (INPV) of El Harrach especially the laboratory for locust control.

All authors read and approved the final manuscript

\section{Authors' contributions}

SAZ carried out the experiment and was a major contributor in writing the manuscript. FM conceived and planned the experiments. NA carried out the experiment and revised the manuscript and corrected references. DjB followed the work in the laboratory and in greenhouses. DM assistance in statistical analysis and correction of the manuscript. MH supervised the work. The author(s) read and approved the final manuscript.

\section{Funding}

Not applicable

\section{Availability of data and materials}

Not applicable

\section{Ethics approval and consent to participate}

Not applicable

\section{Consent for publication}

Not applicable

\section{Competing interests}

The authors declare that they have no competing interests.

\section{Author details}

${ }^{1}$ Département de Zoologie Agricole et Forestière, Ecole Nationale Supérieure d'Agronomie, 1 Avenue Hassan Badi, El-Harrach, 16200 Algiers, Algeria. ${ }^{2}$ Department de Botanique, Ecole Nationale Supérieure d'Agronomie, El-Harrach, Algiers, Algeria. ${ }^{3}$ Departamento de Protección Vegetal, Instituto de Investigación y Formación Agraria y Pesquera, IFAPA-La Mojonera, Camino San Nicolás n.1, La Mojonera, 04745 Almeria, Spain.

Received: 29 November 2019 Accepted: 25 March 2020

\section{Published online: 28 April 2020}

\section{References}

Abbassi K, Mergaoui L, Kadiri ZA, Stambouli A, Ghaout S (2015) Effets des extraits de Peganumharmala (Zygophyllaceae) sur le criquet pèlerin (Schistocerca gregariaForskål, 1775). Zool Baetica 13(14):203-217

Adegbite AA, Adesiyan SO (2005) Root extracts of plants to control root-knot nematode on edible soybean. World J Agric Sci 1:18-21

Adegbite AA, Adesiyan SO, Agbaje GO, Omoloye AA (2005) Host suitability of crops under Yam intercrop to root-knot nematode (Meloidogyne incognita Race 2) in South-Western Nigeria. J Agric Rural Dev Trop Subtrop 106:113-118

Andrés MF, González-Coloma A, Sanz J, Burillo J, Sainz P (2012) Nematicidal activity of essential oils: a review. Phytochem Rev 11:371-390

Babaali D, Berrabah DE, Serghine R, Hammache M, Doumandji S (2016) Comparative efficacy of two modes of applications of 1.3-dichloropropene in the control of root-knot nematodes on two varieties of tomato, pepper and some weeds. Adv Environ Biol 10(11):51-60

Babaali D, Roeb J, Hammache M, Hallmann J (2017) Nematicidal potential of aqueous and ethanol extracts gained from Daturastramonium, Daturainnoxia and Daturatatulaon Meloidogyne incognita. J Plant Dis Prot 124:339-348

Bawa JA, Mohammed I, Liadi S (2014) Nematicidal effect of some plants extracts on root-knot nematodes of tomato. World J Life Sci Med Res 3(3):81-87
Behidj-Benyounes N, Dahmene T, Allouche N, Laddad A (2014) Phytochemical, antibacterial and antifungal activities of alkaloids extracted from Peganumharmala (Linn.) seeds of South of Algeria. Asian J Chem 26:29602964

Bhakta S, Das SK (2015) In praise of the medicinal plant Ricinuscommunis L.: a review. Global J Res Med Plants Indigen Med 4(5):95-105

Bliss Cl (1934) The method of probits. Sci. 79:38-39

Chaudhary KK, Haile A, Ayresea ZG, Semereab G, Weldegergish T (2013) Actividad nematicida de malezas de Eritrea sobre el nematodo agallador Meloidogyne incognita (Kofoid y blanco) Chitwood. Nematropica 43:207-215

Costa SDSDR, Santos DA, Ryan MF (2003) Effect of Artemisia vulgaris rhizome extracts on hatching, mortality, and plant infectivity of Meloidogyne megadora. J Nematol 35(4):437-442

Curto G, Dallavalle E, Santi R, Casadei N, D'Avino L, Lazzeri L (2015) The potential of Crotalaria junceaL. as a summer green manure crop in comparison to Brassicaceae catch crops for management of Meloidogyne incognita in the Mediterranean area. Eur J Plant Pathol 142:829-841

Dane Y, Mouhouche F, Canela-Garayoa R, Delpino-Rius A (2015) Phytochemical analysis of methanolic extracts of artemisiaabsinthium L. 1753 (Asteraceae), JuniperusphoeniceaL., and Tetraclinisarticulata (Vahl) Mast, 1892 (Cupressaceae) and evaluation of their biological activity for stored grain protection. Biol Sci 6:30-11

Guenard D, Gueritte-Voegelein F, Potier P (1993) Taxol and taxotere: discovery, chemistry, and structure-activity relationships. Acc Chem Res 26:160-167

Hassan ME, Zahra F, Mina IHL (2013) Anti-nematode effect assessment of PeganumharmalaBased-Products against Meloidogyne javanicaon melon. J Biol 3(5):5-10

Hemlata P, Jyoti V (2018) Bio-Management of root-knot nematode (Meloidogyne incognita) in tomato (Lycopersicon esculeutum L.). Int J Env Rehab Conserv 9(2):60-63

Hussey RS, Barker KR (1973) A Comparation methods of colleting inocula for Meloidogyne spp. including a new technique. Plant Dis Reporter 57:10251028

Javed N, Gowen SR, Inam-ul-Haq M, Abdullah K, Shahina F (2007) Systemic and persistent effect of neem (Azadirachta indica) formulations against root-knot nematodes, Meloidogyne javanica and their storage life. Crop Prot 26:911-916

Kepenekçi I, Erdoğuş D, Erdoğan P (2016) Effects of some plant extracts on rootknot nematodes in vitro and in vivo conditions. Türkiye Entomoloji Derg. 40(1):3-14

Nenaah G (2010) Antibacterial and antifungal activities of (beta)-carboline alkaloids of Peganumharmala $(L)$ seeds and their combination effects. Fitoterapia 81:779-782

Odeyemi IS, Afolami SO, Adigun JA (2013) Plant parasitic nematode relative abundance and population suppression under Chromolaenaodorata (Asteraceae) fallow. Int J Pest Manag. 59:79-88

Rich JR, Rahi GS, Opperman CH, Davis EL (1989) Influence of the castor bean (Ricinuscommunis) lectin (ricin) on motility of Meloidogyne incognita. Nematropica 19:99-103

Wilson CR, Hooser SB (2018) Toxicity of yew (Taxusspp.) alkaloids. In: Veterinary Toxicology, 3rd edn. Elsevier, New York

Wiratno W, Taniwiryono D, Van den Berg H, Riksen JAG, Rietjens IMCM, Djiwanti SR, Kammenga JE, Murk AJ (2009) Nematicidal activity of plant extracts against the root-knot nematode, Meloidogyne incognita. Open Nat Prod J 2: $77-85$

Xia Y, Qi Y, Yu X, Wang B, Cao R, Jiang D (2019) Nematicidal effect against Bursaphelenchusxylophilus of harmine quaternary ammonium derivatives, inhibitory activity and molecular docking studies on acetylcholinesterase. Eur J Plant Pathol. 153:111-122

Zeck WM (1971) Rating scheme for field evaluation of root-knot nematode infestations. Pflanzenschutz Nachrichten 24(1):141-144

\section{Publisher's Note}

Springer Nature remains neutral with regard to jurisdictional claims in published maps and institutional affiliations. 